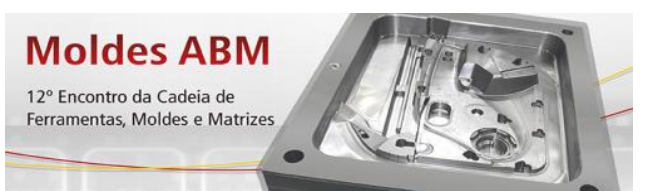

\title{
ESTUDO COMPARATIVO DO DESEMPENHO DE FERRAMENTAS DE CONFORMAÇÃO MANUFATURADAS EM D2 E VF800AT*
}

Vinicius Cardoso Ottani ${ }^{1}$ José Britti Bacalhau²

\section{Resumo}

Os processos de estampagem de materiais de alta resistência requerem o uso de aços ferramenta de alto desempenho, uma vez que a aplicação de pressões elevadas produz o desgaste acelerado das ferramentas de conformação, e até mesmo a ocorrência de falhas catastróficas e prematuras. Frequentemente, o desgaste de ferramentas é superado pelo aumento da dureza dos punções e matrizes, o que implica na diminuição da tenacidade. Esta estratégia, entretanto, não pode ser aplicada em operações de conformação de alta solicitação em que os componentes devem ser tenazes o suficiente para suportar as cargas elevadas envolvidas. A maior dureza retarda o início das trincas, porém também diminui a tenacidade do material, facilitando sua propagação. Uma dureza mais baixa, por outro lado, propicia maior resistência do material à propagação de trincas pela maior tenacidade, porém facilita sua nucleação. Constata-se então, que a relação dureza e tenacidade em aços ferramenta deve ser aprimorada através de um design microestrutural preciso, no qual ambas as propriedades possam ser melhoradas. O presente estudo buscou avaliar a vida útil de punções e matrizes de aços ferramenta AISI D2 e VF800AT limitada por trincas e lascamentos em processos de estampagem. O VF800AT apresentou resultado satisfatório e contribuiu para um aumento de até cinco vezes da vida útil da ferramenta quando comparada com o aço AISI D2. Os ferramentais empregados nesse trabalho foram também caracterizados em laboratório por meio de microscopia óptica e eletrônica de varredura. $\mathrm{O}$ superior desempenho das ferramentas produzidas em aço VF800AT é justificado pela sua superior tenacidade em relação ao AISI D2, devido a uma microestrutura composta de uma matriz de martensita revenida e carbonetos primários em menor fração volumétrica.

Palavras-chave: Conformação a frio; Adesão; Aços ferramenta, VF800AT.

\section{COMPARATIVE STUDY OF FORMING TOOLS PERFORMANCE MANUFACTURED OF D2 AND VF800AT}

\section{Abstract}

Stamping processes of high strength materials require the use of high performance tool steels, since the application of high pressures produces the accelerated wear of the forming tools, and even the occurrence of catastrophic and premature failures. Frequently, tool wear is overcome by increasing the hardness of punches and dies, which implies a decrease of toughness. This strategy, however, cannot be applied in high forming forces operations in which the components must be toughness enough to withstand the pressures involved. Higher hardness delays cracks initiation, but also decreases the material toughness, facilitating their propagation. A lower hardness, on the other hand, provides a greater crack propagation resistance by higher toughness, but facilitates its nucleation. Thus, the hardness and toughness relationship in tool steels must be improved through precise microstructural design, in which both properties can be optimized. The present study evaluates the lifetime of punches and dies of tool steels AISI D2 and VF800AT limited by cracks and chippings in stamping processes. The VF800AT offered satisfactory results and contributed to an increase of up to five times the tool life compared to AISI D2. The tools used in this work were also characterized in the laboratory using optical and scanning electron microscopy. The superior performance of the tools made of VF800AT is justified by their superior toughness compared to AISI D2 due to a microstructure composed of a tempered martensite matrix and lower primary carbide volume fraction.

Keywords: Cold forming; Adhesion; Tool steels; VF800AT.

1 Graduado em Física, Mestrando em Engenharia de Materiais, Ferramentaria, Maxion Wheels, Limeira, SP, Brasil; vinicius.ottani@maxionwheels.com.

2 Engenheiro de Materiais, Mestre em Materiais e Manufatura, Membro da ABM, Gerente de Engenharia de Produto em Ferramental da Villares Metals S.A., Sumaré, SP, Brasil; jose.bacalhau@villaresmetals.com.br.

\footnotetext{
* Contribuição técnica ao $12^{\circ}$ Encontro da Cadeia de Ferramentas, Moldes e Matrizes, 6 e 7 de agosto de 2014, São Paulo, SP, Brasil.
} 


\section{INTRODUÇÃO}

\subsection{Aços ferramentas para trabalho a frio}

Ferramentas para trabalho a frio são usadas em operação de corte, conformação (embutimento, estiramento) e rebarbação a temperaturas inferiores a $200^{\circ} \mathrm{C}$. As características mais importantes são a manutenção do gume cortante para ferramentas de corte e o baixo desgaste para ferramentas de conformação, ambas sujeitas, evidentemente, à condição de tenacidade suficiente para evitar a quebra da ferramenta. Nas operações de conformação, o contato deslizante com o metal a conformar é uma característica importante para o desempenho, sob o ponto de vista do desgaste [1].

$\mathrm{Na}$ confecção da ferramenta torna-se importante a cuidadosa seleção do aço a ser utilizado, levando em consideração fatores como o valor material, as operações de usinagem que serão aplicadas e as propriedades dos materiais. Para atender a aplicações mais críticas, buscam-se em geral aços com dureza na ordem de 60 HRC, obtendo alta resistência ao desgaste a frio. [2].

Os aços ledeburíticos $12 \% \mathrm{Cr}$, como o AISI D2 e D6, são frequentemente aplicados em matrizes de conformação a frio, facas industriais e punções. Tanto o D2 como o D6 possuem resistência ao desgaste gerada por uma matriz martensítica revenida e um elevado volume de carbonetos primários não dissolvidos. Possuem, contudo, baixa tenacidade, estando sujeitos a falhas por trincamento e fratura prematura [3].

Para aplicações em que o principal mecanismo de falha de ferramentais é o desgaste adesivo, têm-se empregado aços de tenacidade mais elevadas como o desenvolvido pela Villares Metals S.A. denominado VF800AT, material que mesmo quando tratado termicamente para durezas de 58-60HRC, apresenta superior tenacidade e consequentemente maior resistência ao desgaste adesivo que 0 tradicional aço AISI D2 [2].

\subsection{VF800AT}

A tenacidade é uma propriedade importante nos aços ferramenta, pois a resistência ao desgaste não depende somente de sua dureza. A maior dureza retarda o início das trincas, porém também diminui a tenacidade do material, facilitando sua propagação. Uma dureza mais baixa, por outro lado, propicia maior resistência do material à propagação de trincas pela maior tenacidade, porém facilita sua nucleação, e em muitas vezes o amassamento das arestas de corte das ferramentas por falta de resistência mecânica.

Um aço para trabalho a frio com propriedades otimizadas de tenacidade e resistência ao desgaste adesivo é o VF800AT, seu projeto de liga foi realizado dentro da composição química base dos aços $8 \% \mathrm{Cr} 0,8 \% \mathrm{C}$, visando manter as características de desgaste, estabilidade dimensional e resistência mecânica típica dos aços ledeburíticos $12 \%$ Cr. A Tabela 1 apresenta um comparativo entre as composições químicas típicas dos aços VF800AT e AISI D2 [4,5].

Tabela 1. Composição química dos aços VF800AT e do aço AISI D2. Valores em porcentagem em massa e balanço em Fe [4,5]

\begin{tabular}{|l|c|c|c|c|c|c|}
\hline Material & $\mathbf{C}$ & $\mathbf{S i}$ & $\mathbf{C r}$ & $\mathbf{M o}$ & $\mathbf{V}$ & $\mathbf{N b}$ \\
\hline VF800AT & 0,85 & 0,90 & 8,00 & 2,00 & 0,50 & 0,15 \\
\hline AISI D2 & 1,50 & 0,30 & 12,00 & 0,95 & 0,90 & - \\
\hline
\end{tabular}

* Contribuição técnica ao $12^{\circ}$ Encontro da Cadeia de Ferramentas, Moldes e Matrizes, 6 e 7 de agosto de 2014, São Paulo, SP, Brasil. 


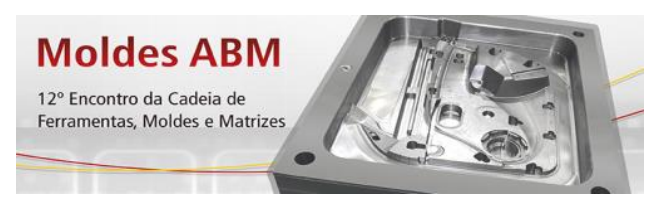

O tratamento térmico de têmpera e revenimento desse aço consistem em austenitização a $1020-1040^{\circ} \mathrm{C}$, podendo ser temperado em óleo, ar ou vácuo, seguido de duplo revenimento a $520-550^{\circ} \mathrm{C}$ para durezas superiores a $58 \mathrm{HRC}$ e melhor resposta a tenacidade do material.

A Figura 1 apresenta os valores de tensão de ruptura em ensaios de flexão a 4 pontos, dos aço VF800AT e D2 tratados termicamente para $60 \mathrm{HRC}$. Analisando o gráfico fica nítida a superior tenacidade do aço VF800AT em relação ao D2 e a potencialização de suas propriedades quando aplicado o ciclo de tratamento térmico descrito acima [5].

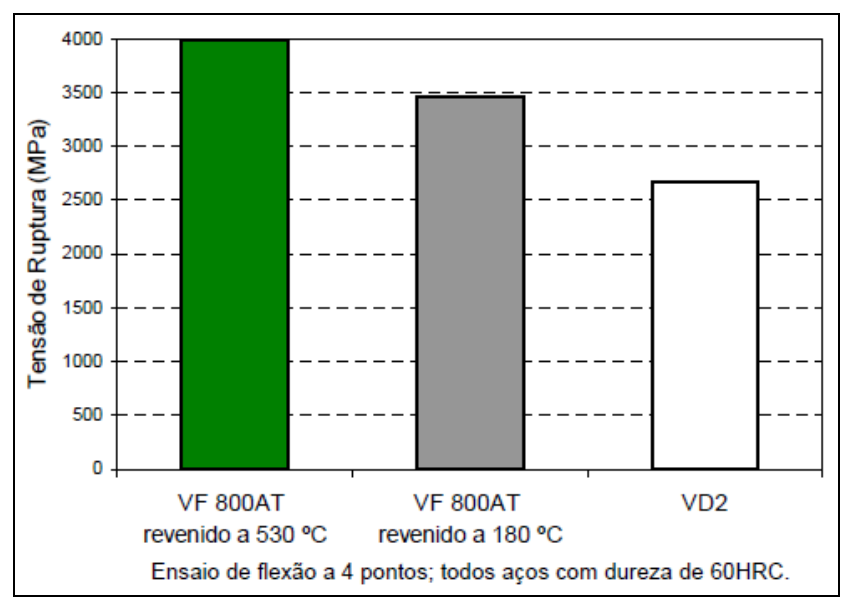

Figura 1. Tensão de ruptura em flexão dos aços VF800AT e AISI D2 [5].

\subsection{Desgaste Abrasivo vs Desgaste Adesivo}

\subsubsection{Desgaste abrasivo}

O desgaste abrasivo é definido como a perda de material provocada pela passagem de uma partícula dura sobre uma superfície de material mais mole [6], como pode ser visualizada na Figura 2 abaixo. De modo geral, a dureza e a microestrutura são dois dos principais fatores que influenciam no desgaste abrasivo. Em aços ferramenta a resistência ao desgaste é obtida pelo endurecimento do material por meio de tratamentos térmicos, obtendo-se uma microestrura mais dura, associada a presença de carbonetos primários dispersos na matriz.

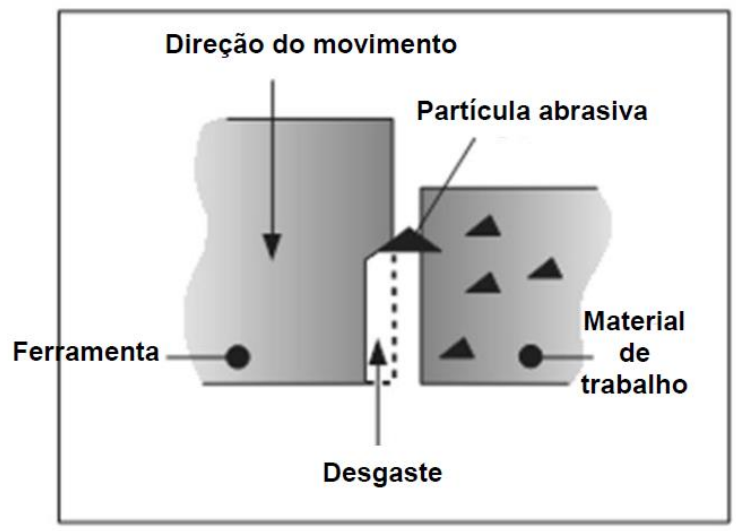

Figura 2: Esquema representando o desgaste do tipo abrasivo. Figura adaptada de [7].

\subsubsection{Desgaste adesivo}

Sólidos tendem a aderir a outros em função de afinidades químicas, distância e pressão de contato nas superfícies. Entre as várias formas de combinação, o

* Contribuição técnica ao $12^{\circ}$ Encontro da Cadeia de Ferramentas, Moldes e Matrizes, 6 e 7 de agosto de 2014, São Paulo, SP, Brasil. 


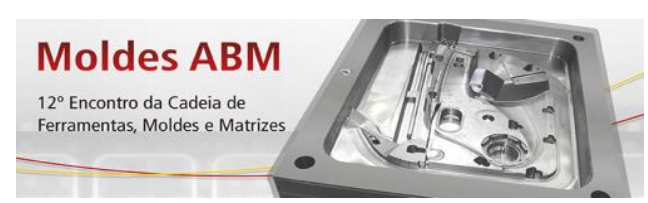

contato metal-metal é a que apresenta elevada força de adesão [6], e o desgaste ocorre uma vez que a adesão envolve colamento e fratura de microasperidades com a transferência do metal que ocorre a partir de uma superfície para a outra. $O$ mecanismo de desgaste por adesão pode ser visualizada na Figura 3 [7]. A adesão é favorecida quando os materiais idênticos deslizam uns contra os outros em condições relativamente limpas. A similaridade existente entre o material da chapa e 0 da ferramenta (contato metal $x$ metal), somado às altas pressões e ao movimento repetitivo ocasionam transferência de material da chapa para a ferramenta, no início a nível microscópico. Esse material que se desprende da chapa permanece soldado ou caldeado à superfície da ferramenta e dá origem a um efeito cumulativo que se intensifica a cada nova peça produzida [8].

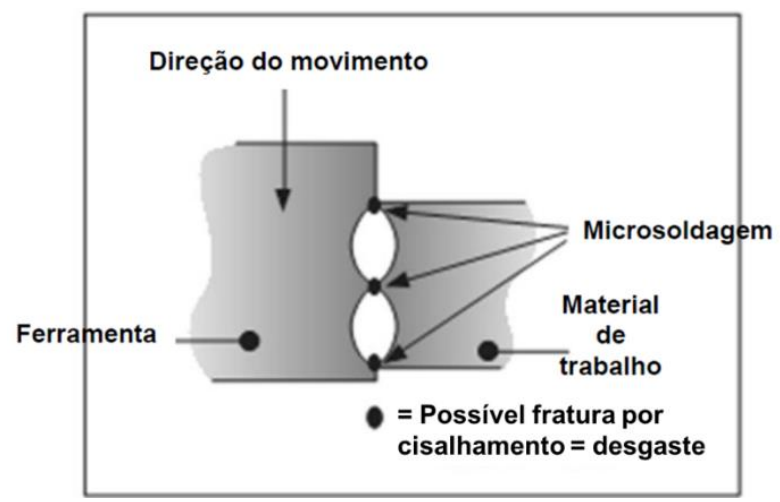

Figura 3: Esquema representando o desgaste do tipo adesivo. Figura adaptada de [7].

\section{MATERIAIS E MÉTODOS}

Foram confeccionados dez punções de conformação e doze matrizes de pré-corte em AISI D2 e VF800AT, sendo respectivamente cinco em cada tipo de aço, na ferramentaria da Maxion Wheels de Limeira. Tais ferramentais foram sujeitos a tratamentos térmicos de tempera e revenidos conforme indicado pelo fornecedor de aço $[4,5]$, para dureza final de $58 \mathrm{HRC}$.

Os ferramentais foram colocados em produção para a fabricação de rodas automotivas de aço, e controlado o número de peças produzidas até o seu final de vida. A Figura 4 apresenta uma imagem ilustrativa com o exemplo dos punções e matrizes testados já em final de vida, os itens analisados são responsáveis pela estampagem de produtos distintos.

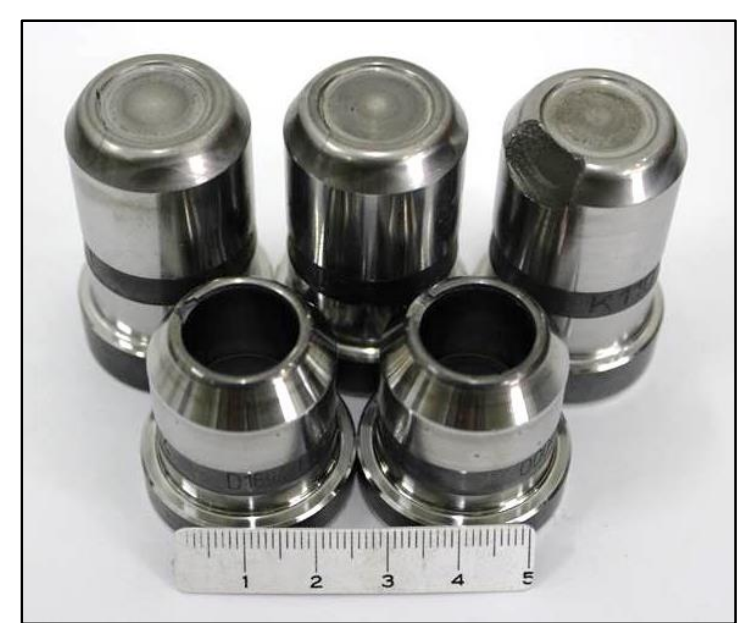

Figura 4. Exemplo dos punções de conformação e matrizes de pré-corte.

\footnotetext{
* Contribuição técnica ao $12^{\circ}$ Encontro da Cadeia de Ferramentas, Moldes e Matrizes, 6 e 7 de agosto de 2014, São Paulo, SP, Brasil.
} 


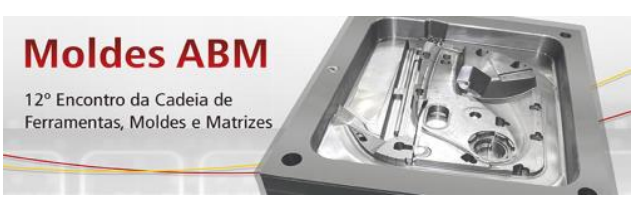

Os punções foram responsáveis pela conformação de um aço bifásico ferritamatensita com adição de cromo como elemento de liga (DP-Cr), o qual apresenta como característica microestrutural ilhas de martensita envoltas em uma matriz ferrítica. O pré-corte é realizado em uma região bastante encruada por operações de estampagem anteriores, que aumentam a resistência mecânica local. Neste caso o material estampado é um aço de alta resistência baixa liga microligado ao nióbio, com uma microestrutura ferrítica e perlítica.

Os ferramentais em seu final de vida foram caracterizados com o objetivo de identificar as causas da falha, e facilitar 0 entendimento da produtividade diferenciada de um mesmo ferramental quando confeccionado em D2 ou VF800AT. Foram realizados ensaios de líquido penetrante para auxiliar na visualização das trincas formadas, caracterização microestrutural por meio de microscopia óptica para avaliação da microesturura dos aços e eletrônica de varredura a análise topográfica dos ferramentais e os mecanismos de desgaste.

\section{RESULTADOS E DISCUSSÕES}

\subsection{Testes de Desempenho}

Com base nos testes de campo realizados, foi verificado que o desempenho tanto dos punções de conformação quanto das buchas de pré-corte manufaturadas em VF800AT foram muito superiores aos ferramentais de AISI D2, a Figura 5 apresenta quantitativamente os resultados. Em relação aos punções de conformação, as ferramentas de VF800AT apresentaram em média um desempenho 5,0 vezes superior àqueles fabricados em D2, já as matrizes de pré-corte o VF800AT superou em 2,5 vezes.
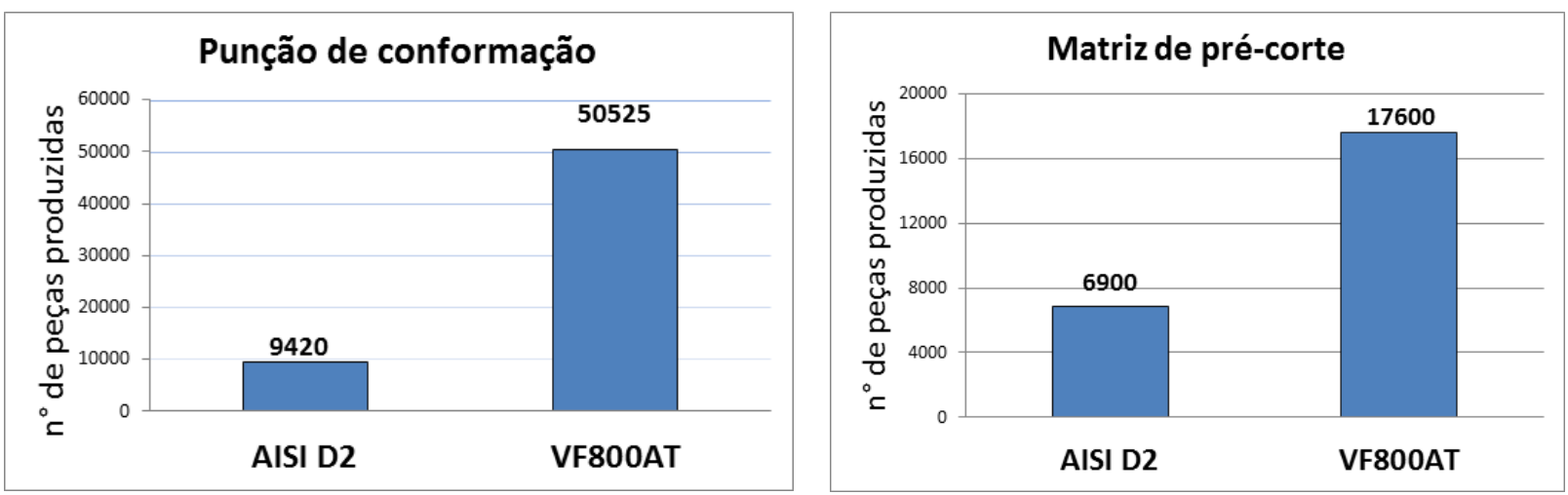

Figura 5. Desempenho dos punções de conformação e matrizes de pré-corte por aço. Média do número de peças produzidas por componente.

\subsection{Ensaio de Líquido Penetrante}

A Figura 6 apresenta a caracterização dos punções e matrizes após ensaio não destrutivo por líquido penetrante. Foi evidenciado que a região em que ocorrem as trincas é exatamente onde há o contato metal-metal (ferramenta-chapa), ou seja, nas bordas externas dos punções e na superfície interna das buchas em que há o deslizamento e consequentemente o desgaste adesivo das ferramentas.

* Contribuição técnica ao $12^{\circ}$ Encontro da Cadeia de Ferramentas, Moldes e Matrizes, 6 e 7 de agosto de 2014, São Paulo, SP, Brasil. 

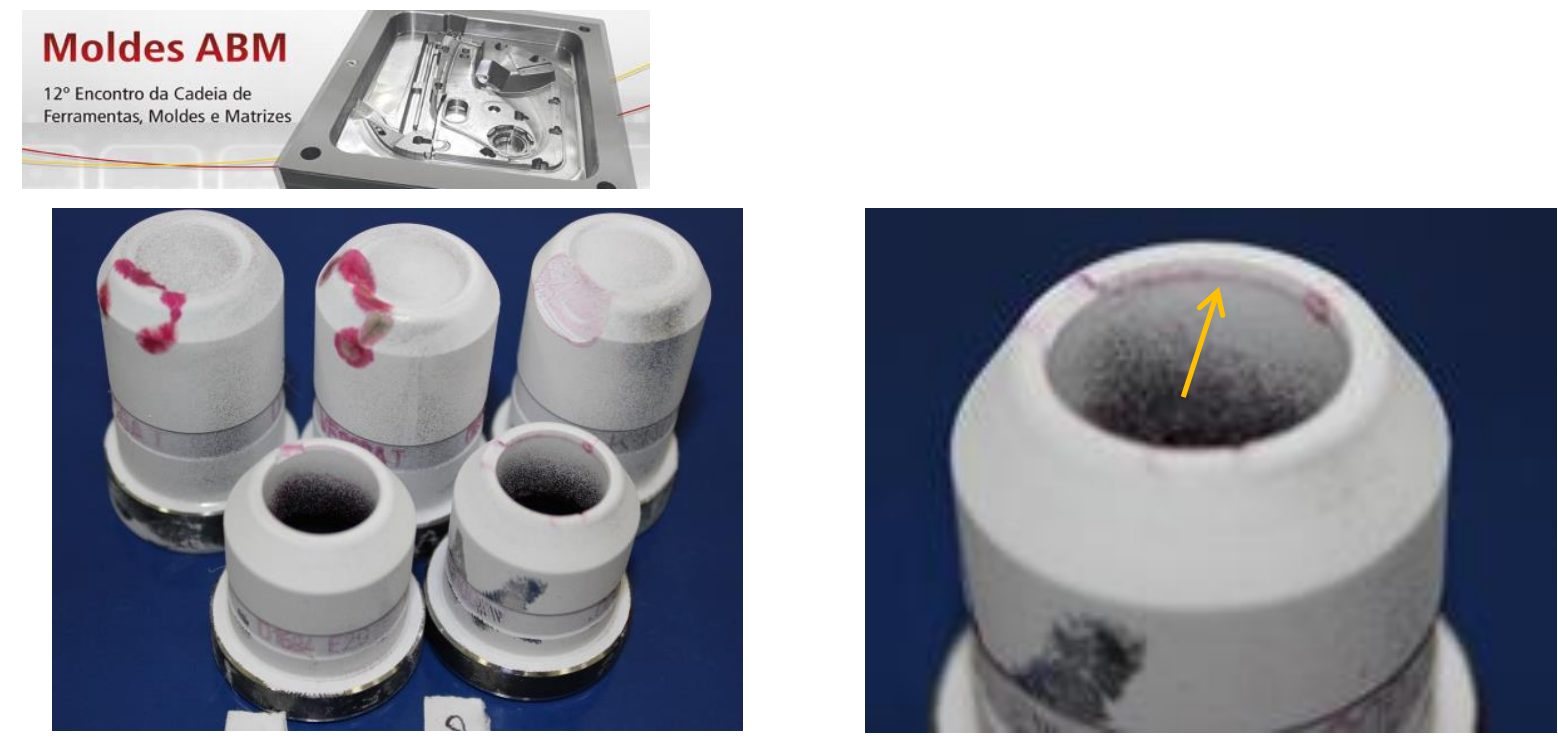

Figura 6. Detalhe das trincas dos ferramentais evidenciadas por meio do ensaio não destrutivo de líquido penetrante. A) Visão geral de dos punções e matrizes. B) Vide seta indicando os detalhes das trincas internas na matriz de pré-corte.

\subsection{Caracterização Metalográfica}

A Figura 7 apresenta a caracterização metalográfica das ferramentas de AISI D2 e VF800AT via microscopia óptica. Note que a presença de carbonetos primários no aço D2 é intensa e muito superior à encontrada no VF800AT. Tais fases atuam como concentradores de tensão contribuindo com uma tenacidade reduzida quando estão presentes a solicitações mecânicas. A formação de tais fases é decorrente do processo de solidificação nas etapas de fabricação do aço, uma maior fração volumétrica de tais fases está presente no aço D2 devido a sua composição química favorável (elevados teores de C e Cr) em comparação ao VF800AT, vide Tabela 1.
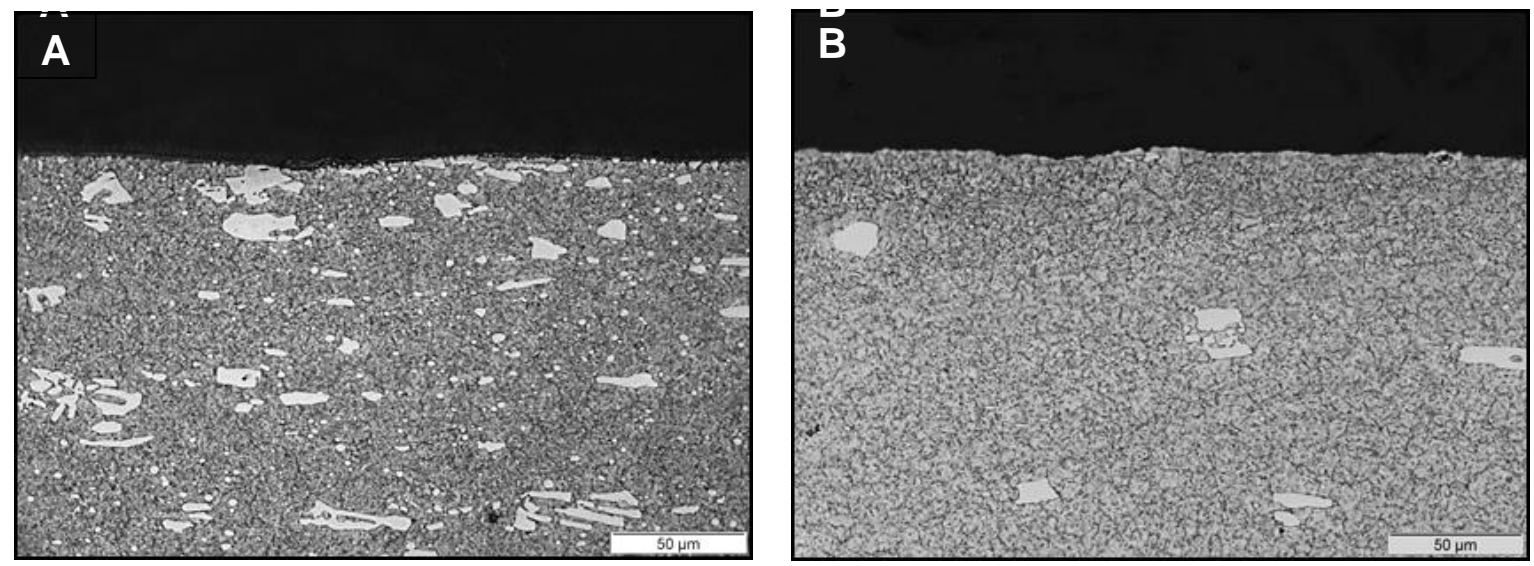

Figura 7. Microestrutura dos aços: A) AISI D2 e B) VF800AT. Aumento 500X. Ataque Nital 4\%.

\subsection{Caracterização Via Microscopia Eletrônica de Varredura}

As buchas de pré-corte foram caracterizadas por meio de microscopia eletrônica de varredura (MEV) com o objetivo de analisar a topografia das ferramentas e identificar os mecanismos de desgaste. A Figura 8 apresenta imagens de tal caracterização em que ficaram evidentes os indícios remanescentes de que o ferramental foi submetido a um processo de desgaste adesivo. No interior da bucha de pré-corte foram encontradas regiões em que houve caldeamento/adesão do aço carbono com o ferramental (regiões incrustadas), devido ao contato metal-metal. As regiões de adesão estão indicadas por setas contínuas na Figura 8. A Figura 9 apresenta os espectros de análises por EDS dos pontos 1 (adesão de aço carbono) e 2 (matriz de aço ferramenta) confirmando os indícios das imagens.

* Contribuição técnica ao $12^{\circ}$ Encontro da Cadeia de Ferramentas, Moldes e Matrizes, 6 e 7 de agosto de 2014, São Paulo, SP, Brasil. 

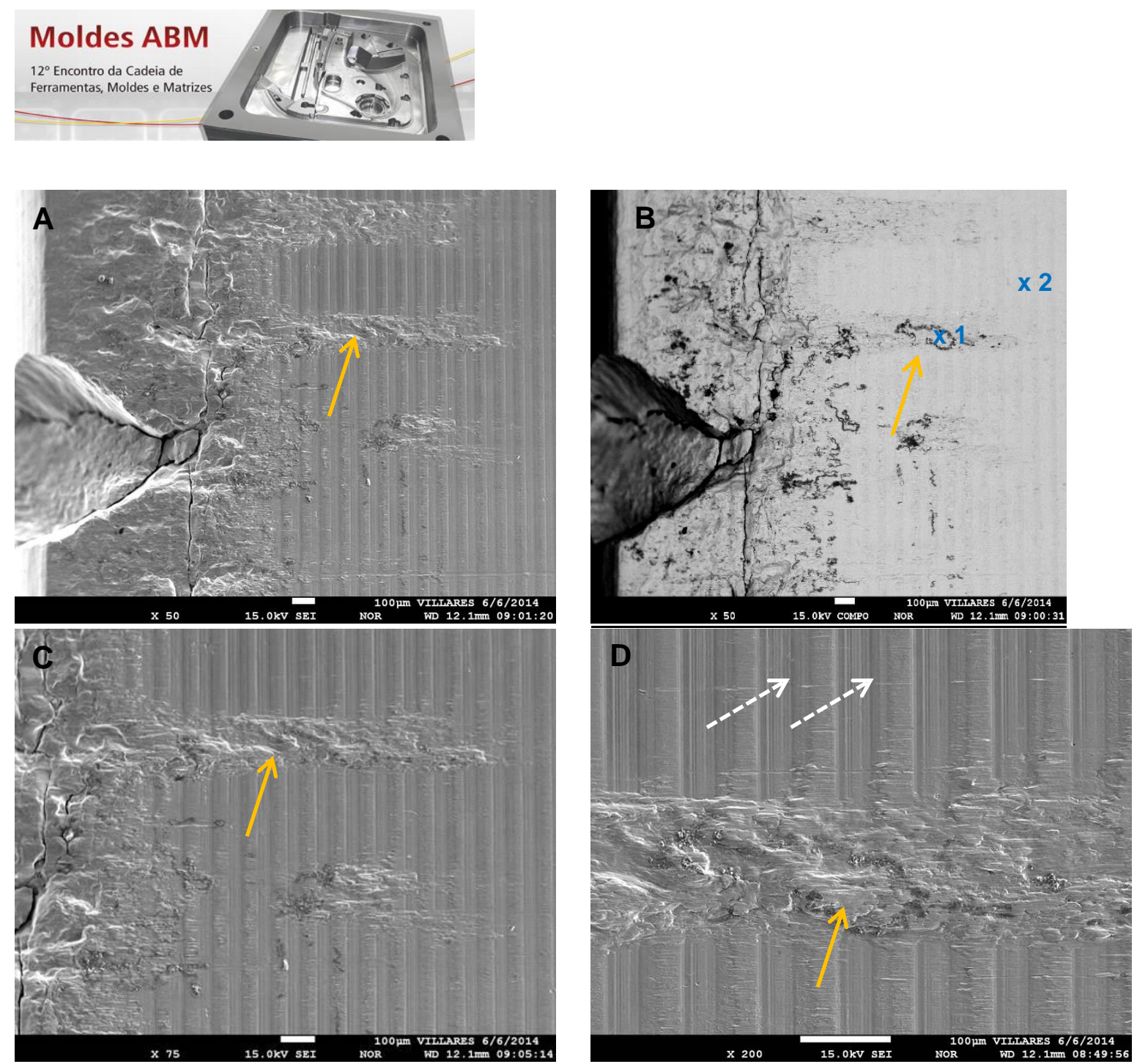

Figura 8. Análise da região interna da bucha de pré-corte por MEV. A) Imagem de elétrons secundários - 50X de aumento. B) Imagem composicional do mesmo campo da imagem A. C) Imagem de elétrons secundários - 75X. D) Detalhe da adesão de aço carbono no ferramental proveniente do processo de conformação - 200X de aumento.

Além disso, pode ser observada na caracterização das buchas a presença de marcas de usinagem que se assemelham a bandas paralelas, vide regiões indicadas por setas tracejadas na Figura 8 "D". Tais marcas usinagem atuam como concentradores de tensão para a nucleação de trincas quando tais ferramentas são submetidas a esforços mecânicos.

Baseado nas caracterizações acima se verifica que a principal razão de as ferramentas de VF800AT terem apresentado um melhor desempenho que as de AISI D2 é devido a sua superior tenacidade em dureza elevadas - 58 a 60 HRC. Tais combinações de propriedades foram obtidas devido a uma microestrutura do material mais tenaz, composta por martensita revenida e carbonetos primários dispersos em menor fração volumétrica que o aço D2.

* Contribuição técnica ao $12^{\circ}$ Encontro da Cadeia de Ferramentas, Moldes e Matrizes, 6 e 7 de agosto de 2014, São Paulo, SP, Brasil. 

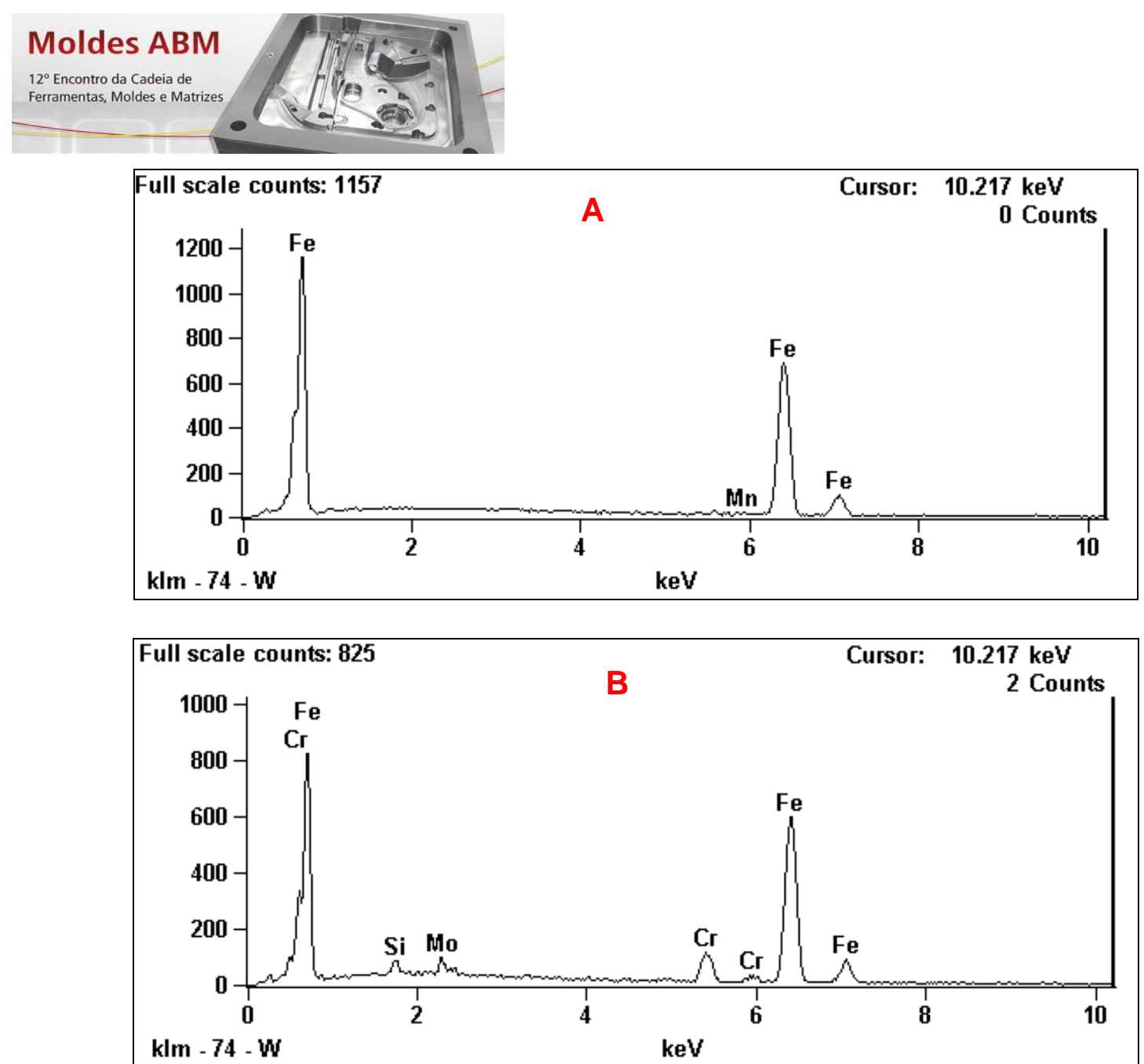

Figura 9. Espectros da caracterização dos pontos 1 e 2 da Figura 8 "B", respectivamente A) região com adesão de aço carbono - detecção apenas do elemento Fe. B) Matriz de aço ferramenta, vide a presença de elementos de liga como $\mathrm{Cr}$ e Mo.

Analisando o processo de conformação de chapas a frio e as características dos ferramentais empregados em tais processos, é previamente conhecido que cedo ou tarde os ferramentais falharão. Dessa forma, de maneira geral os trabalhos de desenvolvimento tecnológico ocorrem no sentido de aumentar os intervalos entre as falhas dos ferramentais. Marcas de usinagem (concentradores de tensão), elevadas tensões de trabalho, adesão metal-metal são apenas alguns dos cenários em que ferramentais atuam para a produção de bens industrializados, dessa forma, materiais com superior tenacidade contribuem favoravelmente para espaçar o intervalo entre falhas, retardando a nucleação e propagação de tricas oriundas do processo produtivo.

\section{CONCLUSÕES}

Os ferramentais produzidos em VF800AT apresentam um intervalo entre falhas que em média superou o AISI D2 em 2,5 vezes para aplicações em buchas de pré-corte e 5,0 vezes para punções de conformação.

A superior tenacidade do VF800AT em relação ao AISI D2 foi o principal contribuinte para espaçar o intervalo entre falhas dos ferramentais.

Os ganhos obtidos em produção com a substituição dos materiais envolvem maior disponibilidade da linha produtiva e de mão de obra, redução peças refugadas e consumo mensal de componentes das matrizes de estampagem. 


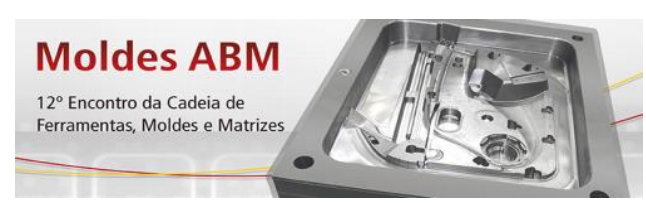

\section{REFERÊNCIAS}

1 Roberts G, Krauss G, Kennedy R. Tool Steels. 5. ed. Material Park: ASM International; 1998

2 Mesquita RA, Barbosa CA. Uma avaliação de desgaste e tenacidade em aços para trabalho a frio. Tecnologia em Metalurgia e Materiais. 2005;2(2):12-18.

3 Mesquita RA, Andrijauskas PS, França LC, Abreu DQ, Barbosa CA., Um novo aço para trabalho a frio de alta tenacidade-VF800AT. In: Anais do 56을 Congresso Anual da ABM; 2001; Belo Horizonte, Brasil. São Paulo: ABM; 2001. p.71-80.

4 Ficha técnica do aço VD2. [acesso em jun. 2014]. Disponível em: www.villaresmetals.com.br.

5 Ficha técnica do aço VF800AT. [acesso em jun. 2014]. Disponível em: www.villaresmetals.com.br.

6 Bressan JD, Schopf RA. Resistência ao desgaste abrasivo e adesivo de aços ferramenta avaliada por meio do ensaio pino-disco. In: 10 Encontro da Cadeia de Feramentas, Moldes e Matrizes; 8 a 10 ago. 2012; São Paulo, Brasil. São Paulo: ABM; 2012.

7 Imagens adaptadas [acesso em jul. 2013]. Disponível em: www.austenit.com/mecanismodefallo.htm.

8 Souza JHC. Mecanismos de atrito e desgaste em conformação de chapas e sua influência na cadeia de produção do ferramental. In: Anais do 9o Encontro da Cadeia de Feramentas, Moldes e Matrizes; 10 a 12 ago. 2011; São Paulo, Brasil. São Paulo: ABM; 2011. 